ORIGINAL RESEARCHARTICLE

\title{
What Are the Boundaries to the Expansion of Digital Labour Platforms? Understanding Uberization through a Cognitive Sustainability Lens
}

\author{
Frédéric Garcias'* and Lucie Noury ${ }^{2}$ \\ IMaître de Conférences, IAE Lille University School of Management, Université de Lille, Lille, France \\ ${ }^{2}$ Audencia Business School, Nantes, France
}

\begin{abstract}
While digital labour platforms are booming, their ability to constitute a sustainable alternative to the managerial firm and to salaried work is questionable. To date, this debate has been approached mainly from legal or political angles, and the organizational sustainability of such platforms remains underexplored. We respond to calls to study more specifically the cognitive capabilities of platforms by mobilizing knowledge-based theories of the firm. We contribute to the literature in three ways: (I) we introduce the concept of 'cognitive sustainability', which we define as the capacity to ensure the integration, conservation and creation of knowledge; (2) we develop a set of propositions aimed at identifying the activities that platforms are most likely to carry out in a cognitively sustainable way; (3) we argue for the possibility of an increased hybridization of digital labour platforms to perform complex activities. Mobilizing knowledge-based theories of the firm to explore new objects such as platforms and taking such hybridization processes into account adds to this body of literature by extending its application domain and taking a more dynamic perspective.
\end{abstract}

Keywords: Uberization; Digital labour platforms; Cognitive sustainability; Knowledge-based theories of the firm

Handling editor: Bertrand Valiorgue; Received: 30 July 20 19; Revised: 3 November 2020; Accepted: 7 April 202 I; Published: I5 December 202 I

W ill we all work for digital labour platforms in the future? This question - which might have seemed absurd a few years ago - is now legitimate given that the rise of independent platforms (or 'uberization') is a phenomenon which, while still emerging, is growing significantly. According to a study by the McKinsey Global Institute in 2016 (McKinsey, 2016), nearly 30\% of the economically active population of the US and the EU-15 were either fully or partly self-employed.The research found that one in six employees in these countries would consider becoming self-employed as their main source of income, suggesting that this mode of work will grow significantly in the coming years and with it the use of digital labour platforms. In order to capture these developments, a team of researchers from the University of Oxford developed the Online Labour Index in 2016. Considering English-language platforms only, they noted a $20 \%$ increase in such vacancies since the creation of the index (Kässi \& Lehdonvirta, 2018). In France, the Conseil d'État observed in 20171 the emergence of 'platform capitalism' (p. II) and

\footnotetext{
Puissance publique et plateformes numériques : accompagner l'ubérisation'.
}

indicated that the total amount of revenue derived from the use of employment platforms had increased 54-fold between 2012 and 2015. They also noted that in the EU, collaborative platforms generated a gross revenue of 28 billion euros in 2015 , twice as much as the year before. Many industries are affected by these transformations, from transport (e.g., Uber and Private Driver) to delivery (e.g., Foodora and Deliveroo) and professional services (e.g., Business Talent Group for consulting and the development of 'virtual law firms' for lawyers).

Some researchers have gone as far as predicting the end of salaried work in the near future (Davis, 2016; Kessler, 2018; Sundararajan, 2016). For Davis, the decline of the managerial firm in favour of platform capitalism is an inexorable outcome of technological development: as the simultaneous development of smartphones and algorithms drastically lower transaction costs, the managerial firm will necessarily become less and less 'competitive', leading to its inevitable decline. Conversely, Fleming, Rhodes and Yu (2019) argue that uberization is much less widespread than first appears because of its structural limits. For them, uberization - which they describe as a pro-market fantasy - has flaws that make it unsustainable, that is, incapable

*Corresponding author: Frédéric Garcias, Email: frederic.garcias@univ-lille.fr 
of reproducing itself in a stable way over time and condemning platforms to certain failure. These debates raise questions about the boundaries to the expansion of uberization: is it destined to spread to all industries and to all types of occupations and functions, and can it become a sustainable dominant form of organizing work?

While the organizational sustainability of platforms has, to date, been mainly considered from the perspectives of technology (Sutherland \& Jarrahi, 20 I 8) and human resource management (Kuhn, 2016; Kuhn \& Maleki, 2017), some authors have recently highlighted challenges related to skills, which are critical in a 'knowledge economy'. For Fleming (20।7), uberization will necessarily raise problems of quality and client trust by shifting the responsibility and cost of training onto workers. For Friedman (2014), the incentives used by platforms are not suited to innovative activities. For others, uberization could provide an opportunity for workers to develop new skills and become more 'agile' (Ashford et al., 2018). Advancing this debate requires an analysis of the cognitive dynamics (i.e., the constitution and renewal of self-employed workers' knowledge and skills) at work within the platforms, which remains largely unknown (Kaine \& Josserand, 2019). In line with these arguments, we mobilize the 'knowledge-based theories of the firm' (Coriat \& Weinstein, 2010), which, as an alternative to patrimonial and transactional perspectives, have proposed a representation of the firm as a collective cognitive entity (Favereau, 1989; Nooteboom, 2009). This detour through theories of the firm enables us to build a conceptual framework aimed at exploring the sustainability of platforms from the perspective of knowledge. Therefore, in this article, we aim to answer the following question: are digital labour platforms cognitively sustainable? We contribute to the emerging literature on uberization in three ways:

I. We introduce the concept of 'cognitive sustainability', which expands the notion of organizational sustainability proposed by Fleming et al. (2019). We show that cognitive sustainability is an essential dimension in the development of digital labour platforms. We operationalize this concept through a review of knowledge-based theories of the firm (Coriat \& Weinstein, 2010), which enables us to define cognitive sustainability as the outcome of three main functions: the integration, conservation and creation of knowledge.

2. We mobilize this heuristic to develop a set of propositions on the cognitive sustainability of digital labour platforms. More specifically, these propositions enable us to characterize the types of activity for which platforms are most likely to be able to ensure the integration, conservation and creation of knowledge, that is, activities characterized by few interdependencies, low levels of complexity and minimal renewal of knowledge.
3. Finally, we use these propositions to analyse the possibilities of the evolution of digital labour platforms, in particular the prospect of an increased 'hybridization' of these platforms, which would integrate an increasing number of managerial firm characteristics in order to ensure their cognitive sustainability. More specifically, we identify three mechanisms that could give rise to this increased hybridization: the weakening of the boundaries between salaried and non-salaried work, the structuring of relationships among self-employed workers and the increased sharing of costs and value.

The remainder of this article is structured as follows. First, we characterize the phenomenon of uberization and the debates around its sustainability. Second, we construct a conceptual framework inspired by knowledge-based theories of the firm. Third, we mobilize this framework to formulate propositions regarding the cognitive sustainability of platforms and discuss their implications. Finally, we explain how we contribute to knowledge-based theories of the firm by extending their scope beyond the managerial firm, through the concepts of cognitive sustainability and cognitive functions, and by making them more dynamic through the identification of hybridization mechanisms.

\section{Uberization and its sustainability}

\section{Uberization: Characterization of a heterogeneous phenomenon}

Several competing terms are used in the literature to describe this major contemporary transformation of capitalism: 'uberization' (Fleming, 2017), 'platform economy' (Acquier, 2018; Kuhn \& Maleki, 2017), 'on-demand' economy (Sundararajan, 2016) and 'gig- economy' (Friedman, 2014). All of these terms refer to the rise in the number of companies using digital platforms to connect clients (whether institutional or individual) with self-employed workers. These platforms, such as Uber, Upwork and Deliveroo, are most often remunerated by commission. However, the terminology encompasses a heterogeneous reality. Digital platforms are characterized by a wide variety of legal statuses and modes of governance. A large majority of platforms are autonomous legal companies, while others are part of a larger group (such as MTurk, a service offered by Amazon). In addition to the pool of independent workers that they link up with clients, some platforms have a number of employees of their own (e.g., Uber and Deliveroo); others do not (e.g., small networks of independent professionals). The freelancers who use these platforms benefit from varying degrees of autonomy, have different levels of qualifications (Kuhn \& Maleki, 2017) and range from the delivery cyclists working for Foodora to the highly qualified IT engineers using Topcoder. 
They are hired for assignments of different lengths; some are paid on a task basis, others per project or per hour (Kuhn \& Maleki, 2017). The platforms are generally associated with the use of algorithms to match clients with self-employed workers but not all of them necessarily do so, not even to assess performance.

Let us consider the example of consulting to illustrate our point. In consulting (as in auditing and legal services), while many professionals have always operated as independents, medium to large firms have historically dominated the market. These professional organizations developed during the end of the $19^{\text {th }}$ and the beginning of the $20^{\text {th }}$ centuries and experienced exponential growth in the 1960s and 1970s. They include the Big Four (PwC, Ernst \& Young, Deloitte and KPMG) and the Big Three (McKinsey, BCG and Bain) and were later joined by large IT consultancies (Accenture, IBM, Capgemini, etc.). In 2013, the 10 largest international firms accounted for $50 \%$ of the sector's overall revenue (O'Mahoney \& Markham, 2013 , p. 50). However, over the past I 5 years - and with more recent rapid growth - independent consultancy platforms have emerged (Christensen et al., 2013; Smets et al., 2017), such as Eden McCallum (UK), Business Talent Group (USA), a-connect (Switzerland), COMATCH (Germany), Colibee (France) and NC Partners On Demand (France). These companies comprise pools of independent consultants who are able to meet the needs of their clients and are paid by commission on completion of the transaction. This business model allows independent consultancy platforms to offer services at a much lower price than traditional consulting firms due to the absence of payroll costs (salaries account for more than 50\% of consulting firm expenditure) and the lower structural costs involved.

We, thus, observe that platforms are now spreading to activities for which salaried work, until recently, was the norm, as is the case, for example, with professional services. This raises a number of questions relating to legal and social issues and what concerns us here - the organization of work.

\section{Uberization: Flash in the pan, niche or future of work? Questions around the sustainability of the phenomenon}

The recent rapid growth of the phenomenon of digital labour platforms gives rise to contrasting interpretations. Uberization is still far from constituting a new norm and only occupies a small part of the world of work. However, some authors argue that it signals the future decline of the managerial firm and the salaried workforce. For example, for Fréry (2016, p. 31 I), the 'domination of the firm is challenged by the emergence of digital platforms that directly connect customers with independent service providers'. The fluidity allowed by technological platforms could take away the 'dependent relationship that is wage-earning [...] its raison d'être' (Fréry, 20 I 6, p. 3|4). Similarly, for Gandini (2019), uberization should not be seen as just another 'non-standard arrangement' or just another means of circumventing the traditional employment relationship. Far from constituting a niche, reserved for specific activities, uberization must be thought of as a 'scalable organizational model that exploits the features of a digital infrastructure to further a 'radical responsibilization of the workforce' on an individual level.' Consequently, researchers must take 'seriously the warnings of an incoming 'uberization' of all work' (Gandini, 2019, p. 1052). Therefore, according to Davis (2016), the logical outcome of uberization would be the prospect of the 'end of the firm' that has dominated since the second industrial revolution (Chandler, 1977).

Fleming et al. (2019) argue against Freeman's (2015) ${ }^{2}$ assertion that 'the uberization of everything is happening.' Noting that predictions regarding the rise of digital platforms are yet to be realised, Fleming et al. aim to reverse the perspective. While many authors predict the unstoppable success of digital platforms, they invite researchers to ask themselves why the 'uber model' has not yet conquered the world and assert that 'there must be something stalling the diffusion of on-demand digital platforms into the wider employment sector' (Fleming et al., 2019, p. I I). Indeed, for them, uberization is impracticable because it constitutes an extreme variant of liberal capitalism that pushes for the responsibilization and atomization of the labour force beyond 'the absolute threshold of what economic agents can sustain' (Fleming et al., 2019, p. II). Furthermore, 'the gig economy - if it were dominant - simply could not reproduce itself in a sustainable manner' (Fleming et al., 2019, p. II). This sustainability has three core dimensions: economic, socio-political and organizational.

From an economic standpoint, numerous studies question the extent of the uberization phenomenon as well as the demographic characteristics of platform workers (Huws et al., 20। 8; Kässi \& Lehdonvirta, 20। 8; Kuhn \& Maleki, 20 I7). Others question the impact of platform use on the income level of individuals (Graham et al., 2017) or the use of entrepreneurship more generally (Burtch et al., 2018).

The socio-political stakes of uberization are the object of numerous studies, particularly from the legal and regulatory viewpoints. These studies examine, more particularly, the nature of the relationship between platforms and 'independent' workers and its legal status (De Stefano, 2015; Westerveld, 2012). Others investigate the risks of increased precariousness for platform workers (Friedman, 2014; Graham et al., 2017; Wood et al., 2019) and the risks of an overall deskilling of the population (Fleming, 2017) that accompanies the rise of micro-work (Casilli \& Posada, 2019). Some authors have sought to characterize different types of dependency relationships on platforms (Kuhn, 2016; Kuhn \& Maleki, 2017), while others

\footnotetext{
2. Freeman, S. (20I5). 'Uberization' of everything is happening, but not every 'Uber' will succed. Huffington Post, April 6, 2015.
} 
have highlighted the risks of the exploitation of the independent workforce caused by the modes of mobilized control (Gandini, 2019; Moisander et al., 2018; Roberts \& Zietsma, 2018; Rosenblat \& Stark, 2016) as well as the identity responses induced (Josserand \& Kaine, 2019; Petriglieri et al., 2019).

To date, the issue of organizational sustainability has been explored to a much lesser extent. It has mainly been approached from two angles: the nature and mediating role of the technology mobilized by platforms (for a review see Sutherland \& Jarrahi, 20I8) and the 'HR' perspective concerning the satisfaction and commitment of the self-employed population (Kuhn, 20 I6; Kuhn \& Maleki, 20 I7). Fleming et al. (2019) also argue that platforms, by placing the burden of training on individuals, will necessarily lead to problems of quality, security and client trust. While some postulate that uberization allows individuals to develop new skills independently and become more agile and adaptable (Ashford et al., 20 I8), Fleming et al. (2019) argue that platforms do not ensure the continuity of interactions between workers, thereby hindering their development and ability to solve complex problems. For Friedman (20I4), platforms are not able to support innovative activities. All these predictions about the capacity of platforms to foster knowledge development are currently speculative and are based neither on a thorough review of the literature nor on empirical findings about the strengths and weaknesses of platforms in this area. Thus, Kaine and Josserand (2019) call for a study of the individual and collective learning mechanisms at play within platforms, which remain largely unknown. In line with such calls, we wish to further explore the cognitive sustainability of digital platforms.

\section{Towards an analysis of the cognitive sustainability of digital labour platforms: A detour through knowledge-based theories of the firm}

To explore the expansion of digital labour platforms is to raise the question of their greater or lesser sustainability compared to the managerial firm. For some, digital labour platforms, by drastically reducing transaction costs, make managerial firms comparatively inefficient (Davis, 2016; Fréry, 2016). This argument is based on Transaction Cost Theory, according to which the main raison d'être ${ }^{3}$ of the managerial firm is to avoid transaction costs (Coase, 1937; Williamson, 1991). However, this viewpoint neglects another body of work in the theory of the

\footnotetext{
3. When we speak of the firm's raison d'être, in line with theories of the firm, we are referring to the firm as a generic institution distinct from the market and not to the raison d'être as a purpose that is specific to each firm. This second meaning has been the subject of many recent developments, summarized by Valiorgue (2020), that are situated at a different level of analysis.
}

firm field that highlights the knowledge-based functions performed by the managerial firm (Coriat \&Weinstein, 2010). The mobilization of this stream of research enables us to accurately define what underpins the cognitive sustainability of the managerial firm and will be helpful to inform the debates instigated by Davis (2016) and Fleming et al. (2019) in particular.

\section{The managerial firm as a sustainable "cognitive entity': A synthesis around three functions}

Theories of the firm aim to understand to what extent the managerial firm is more or less 'efficient' than markets or other governance structures (network, community, etc.). There are many different approaches (Desreumaux \& Bréchet, 2018): those in the mainstream are based on transaction cost or property right theories, while an alternative methodology rests upon the analysis of 'skills' and 'knowledge'. The latter approach is inspired by various fields in organization theory, ${ }^{4}$ such as behavioural theory (Cyert \& March, 1963), resource theory (Penrose, 1959) and evolutionary theory (Nelson \& Winter, 1982), and defines the managerial firm as 'the locus of the management and production of specific knowledge and skills' (Coriat \& Weinstein, 2010, p. 58) or as a collective cognitive entity (Favereau, 1989) aimed at solving complex problems. We synthesize this approach around three major functions of the firm: integrating, preserving and creating knowledge.

\section{The managerial firm as a knowledge-integrating entity}

The first function assigned to the firm is that of being a space in which dispersed individual knowledge and skills can be effectively integrated to provide solutions to complex problems (Grant, 1996). According to the behavioural theory of the firm, the managerial firm is described as 'a system of coordinated actions among individuals and groups whose preferences, information and knowledge differ' (March \& Simon, 1993, p. 299). For Penrose (1959), the firm is a collection of productive resources, by definition heterogeneous, which must be organized to make the most of these resources.

Penrose stresses the need for an 'administrative structure' to integrate resources and find the best possible arrangements, while Grant (1996) asserts the role of the 'employment relationship' (Simon, 195I) in this integration process: the firm, due to its salaried workforce, can create conditions that are more favourable than those of the market for the integration of knowledge. On the one hand, the firm creates conditions of 'propinquity' between individuals, which facilitates their daily

\footnotetext{
4. Due to the diversity of theoretical foundations, these theories inherit the conceptual dispersion of the underlying fields and use fragmented terminology (knowledge, competences, capabilities, resources, etc.).
} 
coordination. On the other hand, it sets up a 'light' incentive structure that prevents opportunistic behaviours, often associated with knowledge transactions, which are by nature uncertain and difficult to specify and, therefore, to contract. Other studies highlight the role of the firm as the locus for the development of 'combinative capabilities' (Kogut \& Zander, 1992). Due to stable individual relationships that make it possible to forge a 'common language' and the existence of 'organizing principles' established by the hierarchy, a specific 'organizational knowledge' that is difficult to transfer outside the firm enables the 'combination' of dispersed knowledge.

\section{The managerial firm as a knowledge-preserving entity}

For Coriat and Weinstein (2010), cognitive theories of the firm, thus, view the firm as an entity capable of not only processing information to solve complex problems (i.e., exceeding the rationality of isolated individuals) but also storing and memorizing the solutions provided in order to apply them to other situations. This 'hereditary mechanism' (Desreumaux \& Bréchet, 2018, p. 30) has long been linked to the identification of 'routines' in behavioural (Cyert \& March, 1963) and evolutionary theories (Nelson \& Winter, 1982). These approaches view managerial firms as 'repertoires' of solutions to problems encountered, which take the form of 'standard operating procedures that relieve the decision-making process' (Coriat \& Weinstein, 2010, p. 74). Firms can, thus, generate learning rents through the repetition and replication of these solutions (Garcias et al., 2015; Kogut \& Zander, 1992) - this has been proposed as an essential cause of the expansion of the managerial firm model (Chandler, 1992).

The literature has also highlighted that the capacity of firms to memorize solutions to complex problems is based on two fundamentally different mechanisms: the externalization or codification of knowledge on the one hand and the transmission of tacit knowledge and socialization on the other. Indeed, routines enable firms to make their capacity for action relatively independent of the individuals who work for the firm (Favereau, 1989, p. 86) and are, therefore, partially insensitive to turnover (Levitt \& March, 1988). However, as the codification of knowledge is imperfect (Hatchuel \& Weil, 1995), it is not possible for firms to completely ignore individual knowledge. Routines operate efficiently only under conditions of relatively stable relationships and the transmission and deployment of tacit, firm-specific capabilities. These capabilities are composed of both individual tacit knowledge, which corresponds to what the literature refers to as specific 'human capital' (Becker, 1962), and the inter-individual experience of the members of the organization, which is linked to the intensity and duration of their common experience recently referred to as 'transactional memory' (Brandon \& Hollingshead, 2004).

\section{The managerial firm as a knowledge-creating entity}

The final cognitive function identified in the literature is the most theoretically debated: the firm as an entity for creating new knowledge. Classical theories of the firm have spoken of the creation of new resources through slack (Penrose, 1959), search processes (Cyert \& March, 1963) and the exploration of unknown solutions (March, 1991) as internal and inherent mechanisms of the firm. More recently, firm theorists have insisted that the often-bureaucratic nature of the firm induces strong resistance to the creation of new knowledge due to 'inertia in a firm's capabilities' (Kogut \& Zander, 1992, p. 396). Indeed, many authors urge the firm to venture beyond its own borders in order to innovate and renew itself (literature on open innovation and ecosystems, crowdsourcing, alliances, etc.).

However, some recent literature has reaffirmed the role of the managerial firm in supporting knowledge creation and innovation (Grandori, 2013; Nonaka et al., 2000; Nooteboom, 2009; O'Sullivan, 2000; Segrestin \& Hatchuel, 20I2). O'Sullivan (2000) has highlighted that the characteristics of the innovation process ('cumulative, collective and uncertain') require resource allocation processes, for which the managerial firm is an ideal vehicle. From a more theoretical standpoint, Nonaka et al. (2000, p. 3) suggest that an 'organization is a place where an individual transcends him/herself through knowledge creation $[\ldots]$ When individuals interact with each other at such a place, one transcends one's own boundary, and, as a result, changes oneself, others and the place itself'. In doing so, they establish a link between the continuity of inter-individual interactions and the cognitive transformation of individuals and organizations. Presenting a similar argument, Segrestin and Hatchuel (2012) have also sought to propose a theory of the firm around the concept of 'collective creation'. They suggest that the invention of the managerial firm (during the $19^{\text {th }}$ century) can be explained by the acceleration of product and process renewal. This resulted in numerous situations, in which skills did not exist prior to their exploitation. The stabilization of the workforce associated with the employment relationship is, thus, explained not only by learning processes that take place over a long period of time but also by the need to protect workers who run the risk of a significant specification of their skills. The 'employment relationship' (Simon, 195I) must then be understood in terms of the 'employee gives up the right to manage [his/her] capacities' in an unknown environment.

\section{The managerial firm as a sustainable cognitive entity: Illustration and synthesis}

The example of consulting firms shows how, in the $19^{\text {th }}$ century, certain activities have been organized to reduce the pressure of competition among independents and to pool specialized knowledge in order to meet the increasingly 
diverse needs of clients (Kirkpatrick \& Noordegraaf, 20 I 5). In these large firms, there is a tendency to emphasize the specialization of consultants (Fincham et al., 2008), and some employees are dedicated to the allocation of work and the composition of teams - working closely with managers - to integrate the specific skills required for each project.

Furthermore, consulting firms organize the preservation of knowledge despite its experiential nature. Indeed, these organizations try to encode as much of their consultants' knowledge as possible through several methods and tools, which consist mostly of a formal and standardized description of the sequence of activities to be carried out on a given type of project (Werr, 2002; Werr \& Stjernberg, 2003). In implementing these methods, consultants often refer to 'cases' - documents produced for other similar projects that can serve as shared models within the organization - as well as to consultants who have worked on these cases in the past with whom they can exchange information to understand how the documents were produced and used (Empson, 2001; Werr \& Stjenberg, 2003). Beyond this knowledge, which is largely specific to each consulting firm (Morris \& Empson, 1998), consultants must also possess a certain amount of tacit knowledge, known as 'socio-political' or 'relational' knowledge (Bloomfield \& Danieli, 1995), which is often acquired during a long process of apprenticeship and is central to the up-or-out career model (Maister, 2012). Finally, consulting firms play a key role in the creation and dissemination of management ideas (Sturdy et al., 2009). Traditional consulting firms coordinate these processes of new knowledge creation, not only through improvisation but also through structured partner-instigated initiatives, with the creation of teams dedicated to research and innovation, and by supporting and replicating local experiments carried out in collaborative projects with clients (Anand et al., 2007; Heusinkveld et al., 2012).
Table I summarizes the three cognitive functions of the managerial firm in the literature.

\section{Are digital labour platforms cognitively sustainable? Propositions and research avenues}

In the previous section, we highlighted three dimensions of the cognitive sustainability of firms: the integration, preservation and creation of knowledge. This enables us to explore the future of digital labour platforms, a question which, to date, has mostly been investigated without considering organizational and cognitive sustainabilities, with the exception of a few studies (Acquier, 2018; Fleming et al., 2019; Kaine \& Josserand, 2019). Here, we investigate the capacity of platforms to take charge of these functions of integration, conservation and creation of knowledge. In our opinion, this requires an extended consideration of the characteristics of the activities carried out. Indeed, the issues of integration, conservation and creation of knowledge do not arise in the same way in all types of activity. Below, we draw on observations concerning the functioning of platforms, based on the development of the consulting example as well as on recent studies of digital labour platforms. This allows us to formulate some propositions regarding the characteristics of the activities, which may influence the sustainability of digital labour platforms.

\section{Are there limits to the expansion of digital labour platforms? Three propositions on their cognitive sustainability depending on the characteristics of their activities}

\section{Limits of digital labour platforms in addressing the need for knowledge integration}

The platforms that are emblematic of uberization have, to date, made little use of the horizontal division of labour.

Table I. The cognitive functions of the managerial firm in 'knowledge-based theory of the firm' literature

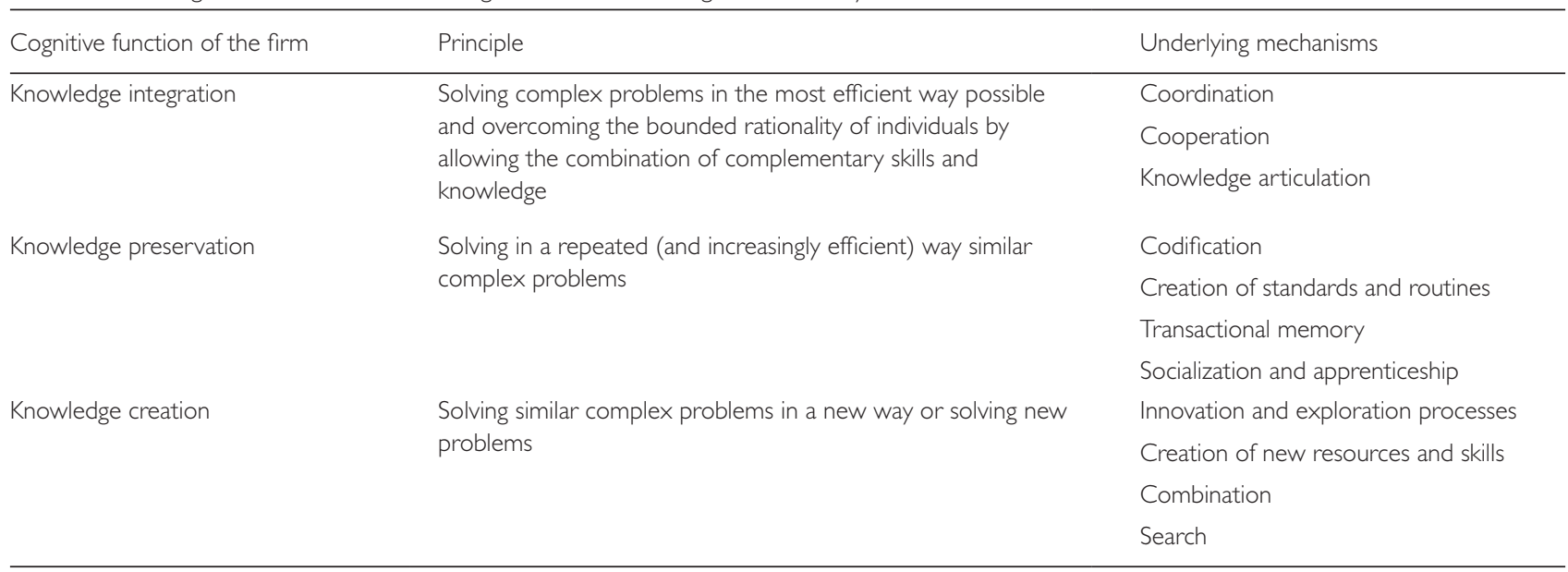


Platform workers, such as private-hire drivers, delivery cyclists and freelance developers, generally carry out the entire work process themselves without needing to interact with others. The division of labour is vertical, akin to neo-Taylorism for some, and mediated by technology. These platforms are, thus, constituted of pools of workers with few differentiated skills who perform homogeneous services. When they offer more diversified services (such as MTurk, Upwork and Business Talent Group), they rarely integrate these skills into a single service. A large proportion of services provided by digital labour platforms do not require the combination of complementary skills. Moreover, we can observe that when a greater integration of specialized knowledge is required, as is the case for certain consulting services for example, this function seems difficult for the platforms to achieve in practice.

For example, the Eden McCallum platform operates without a matching algorithm but through a highly individualized work allocation mechanism: when clients express a need to the sales teams, experts in the field are identified from among the network by a team of 'talent managers', who invite each expert to draw up a commercial proposal that will then be presented to the client. In such a system, based on contracts between specialized consultants and clients, it can be difficult to form teams, organize a collective response and coordinate project work, especially if the experts do not know each other. This can lead clients to criticize the platform for not being able to unite a team despite the quality of the individual profiles (Vermuelen, 2016).

While there is little empirical work directly focused on the integrative capabilities of platforms, we argue that the critical literature on the logics of hyper-individualization at play within such organizations indirectly points to an incompatibility between the modes of incentive and control at work within platforms and the need for knowledge integration. Indeed, several authors have emphasized that platforms subject workers to a form of 'radical responsibilization', whereby 'each individual human capitalist becomes entirely responsible for his or her economic fate' (Fleming, 2017, p. 697) and which is indicated by highly individualized performance measurements and incentives. The literature interprets this as a project of total control over platform workers and of neutralization of collective resistance (Gandini, 20 I8). However, the literature on the theory of the firm indicates that not all activities equally enable this individualization of performance and incentives. When there are many interdependencies in the work process, they obscure the measurement of individual performance (Grant, 1996; Rosen, 1991).

Thus, we argue that, to date, platforms have primarily developed for activities with little interdependence because these are more compatible with the control and incentive mechanisms on which they rely. A high need for knowledge integration could interfere with this logic of individualization.
Proposition 1: Self-employment platforms are more sustainable when their activities can be carried out without

interdependencies between workers

\section{Limits of digital labour platforms in addressing the need for knowledge preservation}

Digital labour platforms are now booming in mostly low-skilled industries (private transport, delivery, etc.), where entry barriers for workers are low: they only need to acquire the material means of work, and no extensive training is required. Some platforms (such as MTurk) deliberately simplify work processes through technology, which divides the activity into elementary units that can be allocated to workers who are paid 'per click'. This simplification strategy has been referred to as 'taskification' by Casilli and Posada (2019) and supports the idea that platforms are suited to activities with the most basic cognitive content possible, not only because this makes business continuity possible despite extreme staff volatility but also because it saves training costs.

However, digital labour platforms are also growing in higher-skilled industries (aeronautics, law, software development, etc.). Here, it seems that other mechanisms are at work to enable these activities to be carried out, such as the selection of freelancers or the organization of communities of practice. We can also observe forms of outsourcing of training through two complementary mechanisms. First, these platforms recruit workers who have already been trained by traditional firms (this is the case for independent aircraft pilots, for example). Second, these platforms rely on the personal initiative of workers to self-train (on their own time and through self-financing) and to organize informal communities of practice (Ashford et al., 20। 8; Fleming, 2017; Schwartz, 2018).

Let us consider the example of consulting once again, which is particularly revealing in this respect. To meet the challenges of knowledge acquisition and preservation, platforms are effectively implementing complementary organizational practices. For example, Eden McCallum invests time in its recruitment processes in order to ensure that the consultants it recruits to be part of its network of independents have the necessary prior acquisition of key knowledge. Indeed, these consultants have all worked for the biggest strategy consulting firms and are handpicked. Only one out of 10 candidates is recruited to join the network. Therefore, Eden McCallum relies to a large extent on traditional strategy consulting firms to train consultants, who, once they have gained experience, can be operational within its platform. However, the platform does not train its own consultants and does not ensure their knowledge remains current. ${ }^{5}$ The cost is, therefore, entirely borne by competing firms and subsequently by the consultants themselves, who are invited to invest in training and to self-organize to share their knowledge.

\footnotetext{
https://edenmccallum.com/future-work-talent/
} 
When platforms operate in more knowledge-intensive sectors, they, therefore, appear to have to delegate knowledge preservation to other actors, including to individuals.

Proposition 2: Digital labour platforms are more sustainable when the activities assigned to their workers are less knowledge intensive

\section{Limits of digital labour platforms in addressing the need for knowledge creation}

Some authors associate the notion of 'platform', understood as a technological infrastructure for intermediation, with technological innovation (Gawer, 2014) or business model innovation (Demil et al., 2018). Similarly, today, the use of crowdsourcing is presented as a way to facilitate the exploration of new knowledge via mechanisms of democratization and extended participation. However, several observations indicate that the organization of digital labour platforms does not encourage the development and introduction of innovations neither in the offer proposed to clients nor in the way in which it is produced and delivered.

The first observation concerns the nature of the activities that are being outsourced. Today, most uberized activities are characterized by a relative stability of knowledge and environment (whether technological, regulatory, etc.). Moreover, while platforms use self-employed workers to carry out their activities for clients, they mostly operate as traditional firms in relation to technological and commercial development activities. Let us consider the symbolic example of Uber, which, in 2019, had more than 20,000 employees and close to an estimated 4 million non-salaried drivers. The employees work on development and IT support, strategy, marketing and communication, and legal support. Digital labour platforms can, therefore, be seen as having outsourced their 'operational centre', retaining a core group of employees in the 'strategic apex', the 'technostructure' or certain support functions; technology and clients have replaced the middle line's direct control of operational work (Mintzberg, 1993). Therefore, platforms do not appear to be able to operate without an underlying firm to organize the renewal of their offers or production services unless they rely completely on the individual initiative of freelancers. This observation is in line with theories that portray innovative activities as organized collective processes, thus requiring a certain stability in relationships (Nonaka et al., 2000; O'Sullivan, 2000). For Friedman, the permanent insecurity introduced by self-employment could make platforms 'less competitive [for technologies] requiring adaptation and innovation' (Friedman, 2014, p. 182) by creating a climate of fear around control and sanction.

Consulting platforms, for example, are not responsible for the proposals made by the freelancers using their platform and act only as an intermediary for them. In practice, several consultants are selected to elaborate a commercial proposal for presentation to the client, who will determine the final choice of provider and approach. Eden McCallum says it is 'agnostic' on the content (Gardner \& McFee, 20 I I). Therefore, in this context, the capacity to propose new services and to renew the knowledge on which they are based is entirely the responsibility of individuals.

Moreover, some studies have highlighted that the algorithmic technology employed by many platforms forces workers to exploit their pre-existing knowledge indefinitely, at the expense of the development of new knowledge. Indeed, for Holford (2019) and Faraj, Pachidi and Sayegh (2018), algorithms and artificial intelligence organize and allocate work on the basis of available data, in particular by assigning individuals tasks that they have already been identified as performing well, thus encouraging forms of circularity and hyper-specialization, which interferes with innovation.

Proposition 3: Digital labour platforms are more sustainable when the activities assigned to their workers require stable knowledge

\section{From the outsourcing of cognitive functions to the increased hybridization of platforms}

Our propositions have enabled us to identify cognitive limits to the expansion of digital labour platforms based on the characteristics of their activities. We argue that the more collective, complex and unstable knowledge involved in the activity is, the less cognitively sustainable a digital labour platform will be. This does not mean that platforms would be totally incapable of being 'efficient' in carrying out such activities: some already are, as mentioned earlier. However, it does mean that, in order to remain efficient in the long term, platforms will necessarily have to resort to 'compensatory mechanisms', by which we mean solutions that they implement, deliberately or in an emergent way, to overcome the cognitive limitations they encounter. We identify two types of mechanism: the first consists of 'outsourcing' the management of cognitive functions; the second involves adopting features that are related to the functioning of the managerial firm. The latter would contribute to a growing hybridization process between the firm and the market at play in these platforms.

\section{The outsourcing of cognitive functions}

Based on existing research and empirical findings, we identify several ways for platforms to outsource the functions of knowledge integration, preservation and creation. Platforms could, indeed, transfer (intentionally or not) the management of these functions either to third-party firms or to the independent workers themselves. The first mechanism involves making other firms (often competitors) bear the 'burden' of 
the training required for the activity, which is higher when the activity is complex. Some platforms, for example in consulting, only work with freelancers who have significant previous experience in conventional firms. A second mechanism consists of making the workers themselves bear the cost of acquiring, maintaining and renewing their knowledge. Ashford et al. (20 I 8) point out, for example, that digital labour platforms call for the 'proactivity' of workers in training and innovation: they 'will need to self-initiate the development of portable skills that allow them to adapt to [...] variable work demands' (Ashford et al., 20 18, p. 30). These authors see this as a means of worker empowerment. For others, such as Fleming (2017), it is part of a trend towards the 'radical responsibilization' of workers, which creates the risk of de-skilling the workforce as workers do not have sufficient incentives to develop and maintain their skills. Others have identified emerging forms of collective action aimed at ensuring knowledge-sharing among workers. In particular, Schwartz has observed the emergence of new types of 'communities of practice' (Schwartz, 20 I 8), initiated by and bringing together platform workers. These communities could reinforce the sustainability of platforms by supporting collective knowledge dynamics (socialization, companionship, exchange of ideas, sharing of practices, etc.). However, they could also present risks to platforms in terms of facilitating forms of collective action and resistance to control. In the future, it will be interesting to observe how platforms position themselves with respect to these communities: between tolerance, control or repression in fear of the resurgence of organized counter-powers.

\section{Towards an increased hybridization of platforms}

Outsourcing creates a relationship of dependence between platforms and third parties (independent contractors, competitors, other organizations, etc.) that may come in the way of vital cognitive functions. In this respect, it seems unsustainable. To counteract this vulnerability, platforms could engage in the internal development of resources and skills and, thus, internalize cognitive functions. This could lead them to incorporate a number of mechanisms that are characteristic of the firm.

Several authors have emphasized the hybrid nature of platforms, which are said to be positioned halfway between the firm and the market (see, for example, Acquier, 20 18; Casilli \& Posada, 2019; Mosmann \& Klutt, 2020). This is demonstrated, in particular, by the fact that platforms, while reproducing the functioning of the market (matching supply and demand, evaluation of the service by consumers, pricing by the market, etc.), generally have the same legal status as firms and have permanent employees to perform strategic, support or technological development functions. Following these observations, we suggest that a hybridization process is at work, one of the determinants of which lies in the cognitive limits of platforms, especially concerning complex activities. Based on the above developments, we identify three dimensions of this hybridization: (I) the boundary between salaried and non-salaried work; (2) the interactions between platform workers; (3) the mechanisms for sharing costs and value.

1. Towards a shift in the boundary between salaried and non-salaried work. Some platforms have set up more formalized processes for 'recruiting' freelancers, enabling them to select the best ones without relying on the market alone. This is the case for many consulting platforms, which see this as a way of ensuring the quality of freelancers' work. Using the same logic, evaluation and sanction mechanisms, beyond client ratings alone, are designed and implemented by certain platforms in order to penalize or even exclude certain freelancers. This increased formalization of selection, evaluation and sanctioning processes by the platforms, which moves them away from purely commercial operations and towards the classic human resources management (HRM) policies of firms. This integration of HRM practices is already documented in the literature (Meijerink \& Keegan, 2019). We propose to consider it as a result of, among other things, the cognitive limitations of platforms. Moreover, as mentioned earlier, platforms already employ salaried workers. We anticipate this will increase as they are confronted with the need to stabilize certain 'key' resources and to secure the exclusive services of workers with skills deemed strategic. Eden McCallum is doing this, recruiting more junior consultants in order not only to relieve some of their freelancers but also to 'keep' them long enough to ensure that they acquire skills regarded as fundamental.

2. Towards an increased structuring of interactions between workers. While platforms may allow freelancers the freedom to organize communities of practice, they may also prefer to structure and control these communities themselves, for example, by organizing events or facilitating exchanges (in person or via the platform), so that individuals share their knowledge or collaborate to create new knowledge. This structuring of exchanges can also be reinforced by increased intervention in work allocation mechanisms, for example, by forming teams of freelancers, especially for more complex services. This can also enable the combination of knowledge and increased cross-learning beyond the algorithmic mechanisms of individual matching. In the future, it might even be conceivable that the need for learning and creativity, requiring greater team and assignment diversity, will impact decisions related to work assignment, moving beyond the existing skill-exploitation logic that prevails within platforms today (Faraj et al., 20 I 8; Holford, 2019). 
Table 2. Key hybridization variables in response to cognitive limitations in digital labour platforms

\begin{tabular}{ll}
\hline Hybridization variables & Mechanisms \\
\hline Boundary between salaried & - More formalized selection and recruitment \\
and non-salaried work & processes for freelancers \\
& - Evaluation and sanction processes handled \\
& by the platform \\
& - Increased hiring of workers under a \\
& salaried contract \\
Relationships among & - Increased structuring of peer communities \\
workers & - Structured knowledge-sharing \\
& arrangements \\
& - Allocation of collective work and team \\
Cost and value sharing & - Emplilding \\
& - Provision and financing of training modules \\
\hline
\end{tabular}

3. Towards new cost and value-sharing mechanisms. Many authors have highlighted that platforms 'capture' part of the value created by freelancers, not only by charging commission on transactions but also by making them responsible for the cost of developing their skills. When we consider highly skilled workers, this inequitable sharing of value and costs could buckle under the effect of its unsustainability for complex and unstable activities. In particular, Friedman (2014) has pointed out that the insecurity of self-employed workers does not encourage risk-taking and innovation. Fleming (2017) has also highlighted a risk of deskilling due to a lack of training incentives. To counter these risks, platforms could retain the most skilled workers and also seek greater stability in relationships. To do this, they could, in the near future, not only be forced to make remuneration more attractive (notably via loyalty and exclusivity bonus mechanisms) but also to bear the direct cost of certain training courses.

We summarize the modalities of this hybridization process in Table 2.

\section{Discussion and conclusion}

In this article, we aim to contribute to debates on the future of digital labour platforms (Davis, 2016; Fleming, 2017; Fleming et al. 2019). In doing so, we contribute to the literature on digital labour platforms on the one hand and to theories of the firm on the other.

We contribute to the literature on digital labour platforms in three ways. First, we respond to calls to explore the sustainability of these platforms (Fleming et al., 2019) as well as their cognitive capabilities (Kaine \& Josserand, 2019) by introducing the concept of 'cognitive sustainability', which develops and operationalizes the concept of organizational sustainability proposed by Fleming et al. (20/9). Second, we propose a synthesis of knowledge-based theories of the firm (Coriat \& Weinstein, 2010), showing that the 'cognitive sustainability' of the firm is associated, in the literature, with its capacity to ensure the integration, conservation and creation of knowledge. We then use this heuristic to identify the types of activities, in which platforms are more likely to be cognitively sustainable (those characterized by few interdependencies, less complex knowledge and relative stability). Third, this enables us to formulate the hypothesis that platforms will become increasingly hybridized in order to overcome their cognitive limits at three distinct levels: the weakening of the boundaries between salaried and non-salaried work; the structuring of relations between freelancers; and the sharing of costs and value. In doing so, we complement the observation, made notably by Acquier (20। 8 ) and Casilli and Posada (2019) of a hybridity of platforms, by making cognitive sustainability as one of the determinants of a 'hybridization process' between the firm and the market at play within platforms.

The introduction of the concept of 'cognitive sustainability', which makes it possible to articulate contributions scattered through a relatively fragmented literature (Desreumaux \& Bréchet, 2018) around three 'cognitive functions', is also a contribution to knowledge-based theories of the firm (Coriat \& Weinstein, 20l0). Moreover, our approach leads us to transpose these 'functions' from the context of the firm to other settings. In doing so, our work invites an examination of neighbouring forms of organization, such as platforms, and a greater focus on the hybridization dynamics at work between the firm and the market (Acquier, 2018; Williamson, 1991). More specifically, while many recent studies have analysed the incorporation of market mechanisms by the firm, this article indicates that organizational forms that are closer to the market, such as digital labour platforms, may incorporate mechanisms characteristic of the firm in order to ensure their cognitive sustainability.

From a managerial viewpoint, this work provides a framework for platform managers wishing to reflect on the cognitive dimensions of their activity and their implications in terms of sustainability. It also allows them to identify action levers with which to address the cognitive limits associated with their mode of organizing. On an institutional level, it can contribute to debates on platform regulation by highlighting a cognitive dimension that is generally overlooked. This article paves the way for several avenues for further research aimed at empirically testing our theoretical propositions on sustainability as well as supporting the hypothesis of increasing hybridization with empirical evidence. The first would be to study in a longitudinal way the economic performance of platforms carrying out the most knowledge-intensive activities. The second would 
be to trace, on a micro-scale, the evolution of the skills of platform employees and the transformations of their organization, particularly in relation to the three dimensions of hybridization identified. A final challenge would be to observe the evolution of relationships (mergers, takeovers, conflicts, etc.) between firms and platforms. Certain knowledge-intensive sectors of activity, such as professional services, engineering, health and IT, would be fertile ground for such studies.

Theoretical perspectives are also emerging for theories of the firm, and this work invites us, in particular, through the consideration of developing objects such as platforms, to reconsider the role of technology in the distribution of activities among the firm, the market and hybrid forms of organizing work. While technological change lowers transaction costs (Davis, 2016), it also affects how the functions of integration, preservation and creation of knowledge operate. Our integrative framework, abstracted from the context of the firm alone, can serve as a basis for analysing this impact and its implications for the firm, the market and alternative forms.

Finally, our approach to the sustainability of platforms has two main limitations. The first is our 'functional' view of platform development to the detriment of an 'institutional' analysis. In so doing, we avoid interpretations of a normative, legal or political nature (Veldman \& Willmott, 2013) for the continuation, slowing down or even the reversal of the expansion of platforms. The second is to give a secondary place to issues of power and resistance (individual or collective) in the dynamics of platforms. However, it seems to us counterproductive to oppose functional approaches with institutional or sociological methodologies. Indeed, we see in the cognitive analysis of the sustainability of platforms a complement to a more socio-political approach. For example, the questions associated with the reclassification of employees as salaried workers will become even more acute as platforms are called upon to become 'managerialized' by virtue of the hybridization process mentioned earlier. Finally, it should be noted that management research generally recognizes the interdependence of issues of power or control on the one hand and knowledge on the other.The future of platforms should, therefore, be determined as much by legal, political and social 'arenas' as by their capacity to respond to the challenges of a knowledge-based economy.

\section{Acknowledgements}

The authors would like to thank the three anonymous reviewers for their careful feedback and valuable advice, as well as the guest editor, Bertrand Valiorgue, for his availability and recommendations that greatly contributed to enhancing the quality of this article.

They also thank Aurélien Acquier, Valentina Carbone, David Massé and Bertrand Valiorgue, the organizers of the ST-AIMS 'Collaborative Economy and Platforms' at the 2018 AIMS conference in Montpellier, the participants of the EGOS 2020 track 'Digitalization and Artificial Intelligence: Reshaping Professional Service Firms, Professions, and Expert Work', as well as Franck Aggeri and Thomas Roulet, for their encouragement and suggested perspectives.

Finally, they thank the members of the strategy team of IAE Lille, especially Alain Desreumaux for the quality of his proofreading and Benoit Demil for his availability, the accuracy of his advice and his support.

The authors have a thought for Johnny Hallyday, who played - without being aware of it - a determinant role in this article.

\section{References}

Acquier, A. (2018). Uberization meets organizational theory: Platform capitalism and the return of the putting-out system. In N. Davison, D. Finck \& J. Infranca (Eds.), Cambridge handbook on law and regulation of the sharing economy (pp. 13-26). Cambridge University Press. doi: $10.1017 / 978 \mid 108255882.002$

Anand, N., Gardner, H. K. \& Morris, T. (2007). Knowledge-based innovation: Emergence and embedding of new practice areas in management consulting firms. Academy of Management Journal, 50(2), 406-428. doi: 10.5465/amj.2007.24634457

Ashford, S. J., Caza, B. B. \& Reid, E. M. (2018). From surviving to thriving in the gig economy: A research agenda for individuals in the new world of work. Research in Organizational Behavior, 38, 23-41. doi: 10.1016/j. riob.2018.11.00।

Becker, G. S. (1962). Investment in human capital: A theoretical analysis. Journal of Political Economy, 70(5), 9-49.

Bloomfield, B. P. \& Danieli, A. (1995). The role of management consultants in the development of information technology: The indissoluble nature of socio-political and technical skills. Journal of Management Studies, 32(I), 23-46. doi: 10.1 I I I/j. 1467-6486. 1995.tb00644.x

Brandon, D. P. \& Hollingshead, A. B. (2004). Transactive memory systems in organizations: Matching tasks, expertise, and people. Organization Science, 15(6), 633-644. doi: 10.1287/orsc. 1040.0069

Burtch, G., Carnahan, S. \& Greenwood, B. N. (20।8). Can you gig it? An empirical examination of the gig economy and entrepreneurial activity. Management Science, 64(I2), 5497-5520. doi: I0. I 287/mnsc.20 I7.29 I6

Casilli, A. \& Posada, J. (2019). The platformization of labor and society. In M. Graham \& W. H. Dutton (Eds.), Society \& the Internet (pp. 293-306). Oxford University Press.

Chandler,A. D. (1977). The visible hand:The managerial revolution in American business. Harvard University Press. doi: 10.2307/j.ctvjghwrj

Chandler, A. D. (1992). Organizational capabilities and the economic history of the industrial enterprise. Journal of Economic Perspectives, 6(3), 79-100. doi: I0.1257/jep.6.3.79

Christensen, C. M.,Wang, D. \& Van Bever, D. (20।3). Consulting on the cusp of disruption. Harvard Business Review, October Issue. 91 ( I0), I06-I I 4

Coase, R. (1937). The nature of the firm. Economica, 4(I 6), 386-405.

Coriat, B. \& Weinstein, O. (2010). Les théories de la firme entre 'contrats' et 'compétences'. Revue d'Économie Industrielle, I29/130, 57-86. doi: | 0.4000/rei.4l 42

Cyert, R. M. \& March, J. G. ( 1963). A behavioral theory of the firm. PrenticeHall. doi: 10.7202/I02I288ar

Davis, G. (20/6). Can an economy survive without corporations? Technology and robust organizational alternatives. Academy of Management Perspectives, 30(2), I29-| 40. doi: I0.5465/amp.20 I5.0067 
Demil, B., Lecocq, X. \& Warnier,V. (20।8). Business model thinking, business ecosystems and platforms: The new perspective on the environment of the organization. M@n@gement, 21(4), 1213-1228. doi: 10.3917/ mana.214.1213

De Stefano, V. (20I5). The rise of the just-in-time workforce: On-demand work, crowdwork, and labor protection in the gig-economy. Comparative Labor Law \& Policy Journal, 37, 47I. doi: 10.21 39/ssrn.2682602

Desreumaux, A. \& Bréchet, J. P. (20 I8). Repenser l'entreprise : Pour une théorie de l'entreprise fondée sur le Projet. Presses Universitaires du Septentrion.

Empson, L. (200 I). Fear of exploitation and fear of contamination: Impediments to knowledge transfer in mergers between professional service firms. Human Relations, 54(7), 839-862. doi: I0. I I77/00 I872670 I547003

Faraj, S., Pachidi, S. \& Sayegh, K. (2018). Working and organizing in the age of the learning algorithm. Information and Organization, 28( I), 62-70. doi: 10.1016/j.infoandorg.2018.02.005

Favereau, O. (1989). Organisation et marché. Revue Française d'Économie, 4(I), 65-96. doi: 10.3406/rfeco.1989.1203

Fincham, R., Clark, T., Handley, K. \& Sturdy, A. (2008). Configuring expert knowledge: The consultant as sector specialist. Journal of Organizational Behavior, 29(8), I |45-I | 60. doi: 10.1002/job.559

Fleming, P. (2017). The human capital hoax:Work, debt and insecurity in the era of Uberization. Organization Studies, 38(5), 691-709. doi: |0.1 |77/01708406 | 6686129

Fleming, P., Rhodes, C. \&Yu, K. H. (2019). On why Uber has not taken over the world.EconomyandSociety,48(4), I-22.doi:I 0. I 080/03085 | 47.20 I9. I 685744

Fréry, F. (2016). L'ubérisation de l'entreprise. In J.-M. Saussois (Ed.), Les organisations : état des savoirs (pp. 3||-3|5). Sciences Humaines. doi: 10.3917/sh.sauss.2016.01

Friedman, G. (2014). Workers without employers: Shadow corporations and the rise of the gig economy. Review of Keynesian Economics, 2(2), I7|-|88. doi: 10.4337/roke.2014.02.03

Gandini, A. (2019). Labour process theory and the gig economy. Human Relations, 72(6), 1039-1056. doi: 10.1 177/00187267|8790002

Garcias, F., Dalmasso, C. \& Sardas, J.-C. (2015). Paradoxical tensions in learning processes: Exploration, exploitation and exploitative learning. M@n@gement, 18(2), 156-178. doi: 10.3917/mana.182.0156

Gardner, H. K. \& McFee, E. (20I I). Eden McCallum:A network-based consulting firm (A and B). HBS Case 410-056 and 4II-027, September 2009 and July 2010

Gawer, A. (20/4). Bridging differing perspectives on technological platforms: Toward an integrative framework. Research Policy, 43(7), 1239-1249. doi: 10.1016/j.respol.2014.03.006

Graham, M., Hjorth, I. \& Lehdonvirta,V. (2017). Digital labour and development: Impacts of global digital labour platforms and the gig economy on worker livelihoods. Transfer: European Review of Labour and Research, 23(2), | 35-| 62. doi: I0. I |77/| 0242589 | 6687250

Grandori, A. (Ed.). (2013). Handbook of economic organization: Integrating economic and organization theory. Edward Elgar Publishing.

Grant, R. M. (1996). Toward a knowledge-based theory of the firm. Strategic Management Journal, 17(S2), 109-122. doi: 10. I002/smj.4250 I7I I 10

Hatchuel, A. \& Weil, B. (1995). Experts in organizations: A knowledge-based perspective on organizational change. De Gruyter.

Heusinkveld, S., Benders, J. \& van den Berg, R. J. (2012). New practice development in professional service firms: The role of market sensing. In M. Reihlen \& A. Werr (Eds), Handbook of research on entrepreneurship in professional services (pp. 202-218). Edward Elgar Publishing. doi: 10.4337/9781781009109.00022

Holford, W. D. (2019). The future of human creative knowledge work within the digital economy. Futures, 105, 143-154. doi: 10.1016/j. futures.2018.10.002
Huws, U., Spencer, N. H. \& Syrdal, D. S. (2018). Online, on call:The spread of digitally organised just-in-time working and its implications for standard employment models. New Technology, Work and Employment, 33(2), | |3-129. doi: 10. I | | |/ntwe. I2 | | |

Josserand, E. \& Kaine, S. (2019). Different directions or the same route? The varied identities of ride-share drivers. Journal of Industrial Relations, 6 I (4), 549-573. doi: 10.1 177/002218561984846|

Kässi, O. \& Lehdonvirta, V. (20|8). Online labour index: Measuring the online gig economy for policy and research. Technological Forecasting and Social Change, 137, 24I-248. doi: 10.1016/j.techfore.2018. 07.056

Kessler, S. (2018). Gigged:The gig economy, the end of the job and the future of work. Cornerstone.

Kirkpatrick, I. \& Noordegraaf, M. (20I5). Organizations and occupations: Towards hybrid professionalism in professional service firms? In L. Empson, D. Muzio, J. P. Broschak \& B. Hinings (Eds.), The Oxford handbook of professional service firms (pp. 238-254). Oxford University Press. doi: 10.1093/oxfordhb/9780199682393.013.6

Kaine, S. \& Josserand, E. (2019). The organisation and experience of work in the gig economy. Journal of Industrial Relations, 6/ (4), 479-501. doi: 10.1 177/0022185619865480

Kogut, B. \& Zander, U. (1992). Knowledge of the firm, combinative capabilities, and the replication of technology. Organization Science, 3(3), 383-397. doi: 10.1287/orsc.3.3.383

Kuhn, K. M. (2016). The rise of the 'Gig Economy' and implications for understanding work and workers. Industrial and Organizational Psychology, 9(I), 157-162. doi: 10.1017/iop.2015.129

Kuhn, K. M. \& Maleki, A. (2017). Micro-entrepreneurs, dependent contractors, and instaserfs: Understanding online labor platform workforces. Academy of Management Perspectives, 3 I (3), I83-200. doi: 10.5465/ amp.2015.0 I I I

Levitt, B., \& March, J. G. (1988). Organizational learning. Annual Review of Sociology, I4(1), 319-338.

Maister, D. H. (2012). Managing the professional service firm. Simon and Schuster.

March, J. G. (199|). Exploration and exploitation in organizational learning. Organization Science, 2(I), 7I-87.

March, J. G. \& Simon, H. A. (1993). Organizations revisited. Industrial and Corporate Change, 2(3), 299-316. doi: 10.1093/icc/2.3.299

McKinsey. (2016). Independent work: Choice, necessity and the gig-economy.

Meijerink, J. \& Keegan, A. (2019). Conceptualizing human resource management in the gig economy. Journal of Managerial Psychology, 34(4), 214-232. doi: 10.1 108/JMP-07-2018-0277

Mintzberg, H. (1993). Structure in fives: Designing effective organizations. Prentice-Hall, Inc.

Moisander, J., Groß, C. \& Eräranta, K. (20 I 8). Mechanisms of biopower and neoliberal governmentality in precarious work: Mobilizing the dependent self-employed as independent business owners. Human Relations, 7/ (3), 375-398. doi: 10.1 177/0018726717718918

Morris, T. \& Empson, L. (1998). Organisation and expertise: An exploration of knowledge bases and the management of accounting and consulting firms. Accounting, Organizations and Society, 23(5-6), 609-624. doi: 10.1016/S0361-3682(98)00032-4

Mosmann, P. C. \& Klutt, J. (2020). Market, hierarchy, or clan? Types of governance in the sharing economy. In I. Maurer, J. Mair \& A. Oberg (Eds.), Theorizing the sharing economy: Variety and trajectories of new forms of organizing Research in the Sociology of Organizations, vol.66, pp. 25-54. Emerald Publishing Limited.

Nelson, R. R. \& Winter, S. G. (1982). An evolutionary theory of economic change. Harvard University Press. 
Nonaka, I., Toyama, R. \& Nagata, A. (2000). A firm as a knowledge-creating entity: A new perspective on the theory of the firm. Industrial and Corporate Change, 9(I), I-20. doi: 10.1093/icc/9.1.I

Nooteboom, B. (2009). A cognitive theory of the firm: Learning, governance and dynamic capabilities. Edward Elgar Publishing. doi: I 0.4337/978 I 848447424

O'Mahoney, J. \& Markham, C. (20।3). Management consultancy. Oxford University Press.

O'Sullivan, M. (2000). The innovative enterprise and corporate governance. Cambridge Journal of Economics, 24(4), 393-4 I 6. doi: I 0. I093/cje/24.4.393

Penrose, E.T. (1959). The theory of the growth of the firm. Oxford University Press. doi: I0.1093/0198289774.001.0001

Petriglieri, G., Ashford, S. J. \& Wrzesniewski, A. (2019). Agony and ecstasy in the gig economy: Cultivating holding environments for precarious and personalized work identities. Administrative Science Quarterly, 64(I), |24-170. doi: | 0.1 | 177/000 | 8392 | 8759646

Roberts, A. \& Zietsma, C. (2018). Working for an app: Organizational boundaries, roles, and meaning of work in the 'On-demand' Economy. In L. Ringel, P. Hiller \& C. Zietsma (Eds.), Towards permeable boundaries of organizations?, Research in the Sociology of Organizations (vol. 57, pp. 195-225). Emerald Publishing Limited. doi: I0.1 108/ S0733-558X20 I 8000005700 |

Rosen, S. (1991). Transactions costs and intemal labor markets. In O. E. Williamson \& S. G. Winter (Eds.). The nature of the firm (pp. 75-89). Oxford University Press.

Rosenblat, A. \& Stark, L. (2016). Algorithmic labor and information asymmetries: A case study of Uber's drivers. International Journal of Communication. 10, 3758-3784. doi: 10.2139/ssrn.2686227

Schwartz, D. (20 I8). Embedded in the crowd: Creative freelancers, crowdsourced work, and occupational community. Work and Occupations, 45(3), 247-282. doi: I 0.1 | 777/07308884 | 8762263

Segrestin, B. \& Hatchuel, A. (20 I 2). Refonder l'entreprise. Le Seuil.

Simon, H. A. (195I). A formal theory of the employment relationship. Econometrica: Journal of the Econometric Society, 19(3) 293-305. doi: $10.2307 / 1906815$
Smets, M., Morris, T., von Nordenflycht, A. \& Brock, D. M. (2017). 25 years since 'P2': Taking stock and charting the future of professional firms. Journal of Professions and Organization, 4(2), 9|-|1।. doi: 10.1093/jpo/jox006

Sturdy, A., Clark, T., Fincham, R. \& Handley, K. (2009). Between innovation and legitimation - Boundaries and knowledge flow in management consultancy. Organization, I 6(5), 627-653. doi: I 0. I I 77/ I 350508409338435

Sundararajan, A. (2016). The sharing economy: The end of employment and the rise of crowd-based capitalism. MIT Press.

Sutherland,W. \& Jarrahi, M. H. (20 I 8). The sharing economy and digital platforms: A review and research agenda. International Journal of Information Management, 43, 328-341. doi: I0.10 I 6/j.jijinfomgt.20 I 8.07.004

Valiorgue, B. (2020). La raison d'être de l'entreprise. Presses universitaires Blaise Pascal.

Veldman, J. \& Willmott, H. (2013). What is the corporation and why does it matter? M@n@gement, 16(5),605-620. doi: 10.39।7/mana.165.0605

Vermuelen, F. (2016). Eden McCallum: Consulting redefined. London Business School case study. LBS Ref: CS- I8-007 HBP: LBS I 30 January 2016.

Werr, A. (2002). The internal creation of consulting knowledge: A question of structuring experience. In L. Engwall \& M. Kipping (Eds.), Management consulting: Emergence and dynamics of a knowledge industry (pp. 91-108). Oxford University Press.

Werr, A. \& Stjernberg, T. (2003). Exploring management consulting firms as knowledge systems. Organization Studies, 24(6), 88I-908. doi: 10.1 1 177/0170840603024006004

Westerveld, M. (2012). The 'new' self-employed: An issue for social policy? European Journal of Social Security, 14(3), 156-173. doi: 10.1177/ |3882627|20|40030 |

Williamson, O. E. (1991). Comparative economic organization:The analysis of discrete structural alternatives. Administrative Science Quarterly, 36(2) 269-296. doi: 10.2307/2393356

Wood, A. J., Graham, M., Lehdonvirta, V. \& Hjorth, I. (2019). Good gig, bad gig: Autonomy and algorithmic control in the global gig economy. Work, Employment and Society, 33(I),56-75. doi: I 0.1 177/09500 I 70 I 87856I6 